\title{
Maternal Marijuana Use During Lactation and Infant Development at One Year
}

\author{
SUSAN J. ASTLEY*1 AND RUTH E. LITTLE† \\ *Department of Pediatrics, University of Washington, Seattle, WA 98195 \\ †Department of Epidemiology, University of Michigan, Ann Arbor, MI 48109
}

Received 25 May 1989

\begin{abstract}
ASTLEY, S. J. AND R. E. LITTLE. Maternal marijuana use during lactation and infant development at one year. NEUROTOXICOL TERATOL 12(2) 161-168, 1990. - Prenatal marijuana exposure is associated with adverse perinatal effects. Very little is known about the effect of postnatal marijuana exposure on infant development. Postnatal exposure can result from maternal use of marijuana during lactation. Delta-9-tetrahydrocannabinol (THC) transfers and concentrates in the mother's milk and is absorbed and metabolized by the nursing infant. The present study investigated the relationship between infant exposure to marijuana via the mother's milk and infant motor and mental development at one year of age. One hundred and thirty-six breast-fed infants were assessed at one year of age for motor and mental development. Sixty-eight infants were exposed to marijuana via the mother's milk. An additional 68 infants were matched to the marijuana-exposed infants on pre- and postpartum maternal alcohol and tobacco use. Marijuana exposure via the mother's milk during the first month postpartum appeared to be associated with a decrease in infant motor development at one year of age.
\end{abstract}

Lactation Marijuana Postnatal exposure Infant development

THE reported use of marijuana among pregnant women varies from five to 34 percent $(4,7,8,18)$. Fetal effects associated with prenatal exposure to marijuana include decreased birth weight $(10,21)$ increased frequency of preterm delivery $(2,7)$, increased labor and delivery complications $(8,9)$ and altered visual, tremor and startle responses in neonates $(3,6)$. Many of these findings remain suggestive due to the number of factors associated with marijuana use which are difficult to control in clinical and epidemiologic studies.

In contrast to the volume of literature addressing adverse effects of prenatal marijuana exposure, little attention has been directed towards postnatal marijuana exposure. Infant exposure via the mother's milk is of particular importance in light of the fact that delta-9-tetrahydrocannabinol (THC), the principal psychoactive component of marijuana, transfers into the mother's milk at levels reported at eight times that in maternal blood (17). Not only do nursing infants absorb and metabolize THC, but their exposure occurs at a time when growth and development, particularly glial and myalin formation in the central nervous system, is progressing at a rapid rate.

The purpose of this study was to investigate the relationship between infant marijuana exposure via the mother's milk and infant motor and mental development at one year of age in a predominantly middle class, low-risk population.

\section{METHOD}

\section{Subject Selection}

The research presented here uses data obtained in a previous prospective investigation of maternal diet, drinking and smoking during lactation on infant growth and development. There were three parts to the original prospective study. First, validity of self-reported alcohol, tobacco and other drug use and the reliability of the maternal interview process was confirmed $(13,15)$. Next, descriptive studies were conducted to contrast the dietary habits and alcohol and tobacco use of lactating and nonlactating women $(14,19,20)$. And finally, an infant assessment study was conducted that explored the relationship of alcohol use during lactation and infant development at one year of age (12).

Subjects in the previous prospective study were members of Group Health Cooperative of Puget Sound, a health maintenance organization in Seattle, WA. All prenatal patients receiving care between May 1, 1982 and July 1, 1984 were contacted by the Cooperative in their sixth month of pregnancy regarding possible study participation. An informed consent form with a full explanation of study procedures was provided. Seventy-four percent $(5,298)$ of the prenatal patients responded and completed a mailed screening questionnaire detailing their alcohol and tobacco use both before and during pregnancy, some dietary information, and their plans to lactate. These patients constituted a screened pool.

Three months after delivery, 400 mother/infant pairs had been selected from the screened pool to participate in the previous infant assessment study cited above (12). Selection was based on maternal pre- and postpartum use of alcohol reported in personal interviews that were conducted at one and three months postpartum.

When the sample of 400 had been selected, we found that a substantial number of women reported postpartum use of mari-

${ }^{1}$ Requests for reprints should be addressed to Susan J. Astley, M.S., Department of Pediatrics RD-20, RR314, Health Sciences Building, University of Washington, Seattle, WA 98195. 
juana $(n=82)$. Seventeen additional women who reported marijuana use during pregnancy only were then taken from the screened pool to enrich the sample $(n=417)$ and provide sufficient power to conduct the pilot study described here. At one year of age, all 417 infants were assessed for motor and mental skills using the Bayley Scales of Infant Development (1).

From among the 417 infants with one-year assessments, those who had been breast-fed for at least two weeks with less than 16 ounces of supplemental formula per day were eligible for the present study. Three-hundred twenty-three of the 417 infants met this criteria. Of these 323 mother/infant pairs, 68 mothers $(21 \%)$ reported marijuana use during the first and/or third month of lactation. The infants of these 68 mothers represent the "lactationmarijuana-exposed" group in this study. From the remaining 255 breast-fed infants whose mothers did not use marijuana during lactation (lactation-marijuana-unexposed), 68 were matched to the marijuana-exposed group on maternal alcohol and tobacco use during pregnancy and during the first and third months postpartum. The groups were also matched, as nearly as possible, on duration of lactation, prenatal marijuana exposure and month of birth. The two cohorts of infants (marijuana exposed and unexposed during lactation) make up the sample of 136 for the pilot study reported here.

\section{Dependent Variables}

The two outcome variables reflecting infant motor and mental development at one year of age were the Psychomotor Developmental Index (PDI) and Mental Developmental Index (MDI) from the Bayley Scales of Infant Development. The Bayley is a widely used infant assessment tool with a standard scoring system and demonstrated validity and reliability. The PDI index provided a measure of the infant's gross motor coordination and finer manipulatory skills of the hands and fingers. The MDI index provided a measure of the infant's problem solving abilities and verbal communication development. The examiners were trained master's level clinicians with specialities in infant development. They were blind to the drug use status of the mother. Interobserver reliability on Bayley scores was maintained at 0.9 or higher.

\section{Independent Variables}

Personal interviews were conducted at one and three months postpartum in the original prospective study to gather detailed information on alcohol and tobacco use, exposure to other drugs (prescriptions, over-the-counter drugs, marijuana and other illegal substances), demographic characteristics, obstetric history, lactation status and use of supplemental formula during lactation. The use of drugs during pregnancy was addressed retrospectively in the one-month postpartum interview. Each subject had been assigned a single interviewer for the duration of the study. The interviewers were women of childbearing age, trained to obtain valid and reliable information. Validity of self-reported drug use was confirmed in an earlier pilot investigation on a sample of 108 randomly selected postpartum women. Self-reported drug use was compared to laboratory tests of drug levels present in body fluids; the proportion of questionable self-reports ranged from 0 to $3 \%$ depending on the drug (13).

Maternal use of marijuana, cocaine, caffeine and other drugs was measured in terms of how often the substance was used, when it was used and how much was used. Alcohol consumption was categorized into beer, wine and liquor and was measured in terms of frequency of use, modal quantity, and maximum quantity per drinking occasion. These measures were converted to average daily ounces of ethanol ingested in a specified period of time
TABLE 1

CHARACTERISTICS OF WOMEN WHO DID AND DID NOT USE MARIJUANA DURING LACTATION

\begin{tabular}{|c|c|c|}
\hline & $\begin{array}{l}\text { Marijuana Use } \\
\text { During Lactation } \\
\qquad(N=68)\end{array}$ & $\begin{array}{c}\text { No } \\
\text { Marijuana Use } \\
\text { During Lactation } \\
(\mathrm{N}=68)\end{array}$ \\
\hline Maternal & & \\
\hline Characteristics & \multicolumn{2}{|c|}{$\mathrm{N}$ or Mean \pm Standard Deviation } \\
\hline \multicolumn{3}{|l|}{ Age (years) } \\
\hline 18 to 29 & 42 & 41 \\
\hline 30 to 41 & 26 & 27 \\
\hline \multicolumn{3}{|l|}{ Race } \\
\hline White & 63 & 68 \\
\hline \multicolumn{3}{|l|}{ Parity } \\
\hline Primiparous & 42 & 39 \\
\hline \multicolumn{3}{|l|}{ Marital status } \\
\hline Married & 57 & 60 \\
\hline \multicolumn{3}{|l|}{ Income } \\
\hline$<\$ 10,000$ & 10 & 4 \\
\hline$\$ 10,000$ to $\$ 25,000$ & 28 & 32 \\
\hline$>\$ 25,000$ & 30 & 32 \\
\hline \multicolumn{3}{|l|}{ Postpartum working status } \\
\hline Employed & 8 & 8 \\
\hline \multicolumn{3}{|l|}{ Education (years) } \\
\hline 10 to 12 & 24 & 23 \\
\hline 13 to 15 & 20 & 25 \\
\hline 16 to 23 & 24 & 20 \\
\hline Maternal height (cm) & $167 \pm 6$ & $166 \pm 6$ \\
\hline Pregnancy weight gain (kg) & $16 \pm 4$ & $15 \pm 5$ \\
\hline \multicolumn{3}{|l|}{ Lactation duration } \\
\hline$\leq$ One month & 10 & 10 \\
\hline Two months & 9 & 7 \\
\hline Three months & 45 & 49 \\
\hline One or more months* & 4 & 2 \\
\hline \multicolumn{2}{|c|}{ lactation $(<16 \mathrm{oz} . /$ day $)$} & \\
\hline Month one & 9 & 10 \\
\hline Month three & 15 & 13 \\
\hline \multicolumn{3}{|l|}{ Infant sex } \\
\hline Female & 30 & 33 \\
\hline Gestation (weeks) & $40 \pm 2$ & $40 \pm 1$ \\
\hline
\end{tabular}

*Lactation status unknown for 2 nd and 3 rd months postpartum.

("AA score") (11). For cigarette use, a nicotine score was determined by multiplying the number of cigarettes smoked per day by the nicotine content of the brand specified. Use of supplemental formula was recorded as no use, $<16$ ounces per day or $>16$ ounces per day.

The primary independent variable in this study was the number of days an infant was exposed to marijuana via the mother's milk during postpartum months one and three. The frequency of maternal marijuana use weighted by the mother's duration of lactation provided an estimate of infant exposure to marijuana via breast milk.

Secondary independent variables which could potentially con- 
TABLE 2

MATERNAL MARIJUANA USE DURING PREGNANCY AND LACTATION

\begin{tabular}{lrrrrrr}
\hline & $\begin{array}{c}\text { Pregnancy } \\
\text { Maternal }\end{array}$ & $\begin{array}{c}\text { Lactation } \\
\text { Month One } \\
\text { Marijuana }\end{array}$ & $\begin{array}{c}\text { Lactation } \\
\text { Month Three } \\
\mathrm{N}=136\end{array}$ & & & \\
Use & $\mathrm{N}$ & $(\%)$ & $\mathrm{N}$ & $(\%)$ & $\mathrm{N}$ & $(\%)$ \\
\hline & & & & & & \\
Frequency & & & & & & \\
$\quad$ Never & 70 & $(52)$ & 81 & $(60)$ & 72 & $(58)$ \\
$\quad<$ once a week & 38 & $(28)$ & 27 & $(20)$ & 22 & $(18)$ \\
$1-4$ times a week & 20 & $(15)$ & 18 & $(13)$ & 18 & $(14)$ \\
$\quad$ Daily & 8 & $(5)$ & 10 & $(7)$ & 13 & $(10)$ \\
Number of times per day & & & & & & \\
$\quad$ & 70 & $(52)$ & 81 & $(60)$ & 72 & $(58)$ \\
1 & 55 & $(40)$ & 47 & $(35)$ & 38 & $(30)$ \\
2 & 7 & $(5)$ & 5 & $(3)$ & 9 & $(7)$ \\
3 to 5 & 4 & $(3)$ & 3 & $(2)$ & 4 & $(3)$ \\
$\quad$ Unknown & 0 & $(0)$ & 0 & $(0)$ & 2 & $(2)$
\end{tabular}

*Eleven subjects selected too late for third month interview.

found the relationship between infant marijuana exposure during lactation and infant development included: 1) Maternal age, height, race, income level, education, marital status, pregnancy history and weight gain, tobacco, coffee, alcohol and psychoactive drug use during pregnancy and lactation and marijuana use during pregnancy; 2) Paternal alcohol and tobacco use before conception and during the postpartum period; 3) Infant gestational age and sex.

Maternal dietary history was gathered in the original study, but previous studies of this population have revealed no association between infant development and maternal nutrition $(12,19)$.

\section{Statistical Analysis}

Standard multiple regression analysis was used to determine if infant exposure to marijuana via breast milk explained a significant proportion of the variance in the infant motor and mental development scores, after controlling for confounding and interaction with other independent variables.

The first stage of analysis began with the transformation of the categorical measures of maternal marijuana use into continuous measures that reflected infant exposure. In utero exposure was represented by the number of days the mother used marijuana in each trimester. Infant exposure via the mother's milk was represented by the number of days the mother used marijuana during postpartum months one and three, weighted by the proportion of

TABLE 3

INFANT MARIJUANA EXPOSURE Exposed During

\begin{tabular}{llc}
\hline Gestation & Lactation & $\begin{array}{c}\text { Number of } \\
\text { Subjects }\end{array}$ \\
\hline NO & NO & 58 \\
YES & NO & 10 \\
NO & YES & 14 \\
YES & YES & 54 \\
\hline
\end{tabular}

days she lactated in each month. For example, an infant whose mother reported daily use of marijuana during postpartum month one and stopped breast-feeding halfway through the month would receive an estimated exposure score of fifteen days. An infant whose mother reported marijuana use every other day and breastfed throughout the month would also receive an exposure score of fifteen days. Women who reported use of less than 16 ounces of supplemental formula during lactation were classified together with women that reported no use of supplemental formula. The effect of supplemental formula use on infant marijuana exposure in this study is addressed in the analysis.

Next, potential confounding variables were identified by assessing their association with both infant developmental outcome (MDI or PDI) and maternal use of marijuana during lactation. Chi-square, regression analysis and ANOVA were used, where appropriate, to evaluate associations of each variable with exposure and outcome. We did not, however, rely on statistical significance to identify potential confounders. Any variable that demonstrated a suggestive association with both exposure and outcome was retained as a potential confounder. All secondary variables identified as confounders were regressed simultaneously with infant marijuana exposure during lactation on infant PDI and MDI outcome measures. Backwards and stepwise variable selection was performed with F-to-enter set at $p=0.05$ and F-to-remove set at $p=0.10$. Pairwise deletion of missing data was employed. Interaction terms between infant marijuana exposure during lactation and each retained secondary variable were computed. Each interaction term was allowed to enter the equation containing the interaction component variables by stepwise selection to determine if any secondary variable significantly modified the effect of marijuana exposure on infant PDI and MDI. Finally, maternal use of cocaine, alcohol and tobacco during pregnancy and lactation were forced into the final equation, one at a time, to verify that addition of the variable did not change the estimate of the primary independent variable.

Differences in maternal characteristics between the women who did and did not use marijuana during lactation were determined by chi-square or the $t$-test. Contrasts and linear trends of mean MDI and PDI scores, stratified by infant marijuana exposure during gestation and lactation were evaluated with one-way ANOVA.

\section{RESULTS}

There were no significant differences between the sociodemographic profiles and infant characteristics of the women who did and did not use marijuana during lactation, as shown in Table 1. Both groups were primarily white, middle class, college-educated women. Age ranged from 18 to 41 with a mean of 28.3 years. Eighty-six percent of the women were married.

The frequency of maternal marijuana use during pregnancy and lactation is presented in Table 2 . Twenty to 24 percent of the women in this study reported using marijuana at least once a week during pregnancy or lactation. The usual dose on each occasion was one joint. Five to ten percent of the women who used marijuana reported smoking two to five joints per day. Of the women who reported using marijuana during pregnancy, $84 \%$ continued to use marijuana during lactation (Table 3 ). This strong correlation between maternal pre- and postpartum marijuana use could not be effectively reduced by matching (Pearson correlation coefficient $=.59$ ). Matching did, however, effectively reduce the correlations between marijuana use during lactation and the preand postpartum use of alcohol and tobacco (Table 4). Alcohol, tobacco and cocaine use during pregnancy and lactation was comparable between the women who did and did not use mari- 
TABLE 4

MATERNAL ALCOHOL, TOBACCO AND COCAINE USE

\begin{tabular}{|c|c|c|c|c|c|c|}
\hline \multirow[b]{2}{*}{ Drug Use } & \multicolumn{3}{|c|}{$\begin{array}{l}\text { Marijuana Use } \\
\text { During Lactation } \\
\quad(N=68)\end{array}$} & \multicolumn{3}{|c|}{$\begin{array}{l}\text { No Marijuana Use } \\
\text { During Lactation } \\
\quad(N=68)\end{array}$} \\
\hline & Mean & (S.D.) & $\mathrm{N}$ & Mean & (S.D.) & $\mathbf{N}$ \\
\hline \multicolumn{7}{|l|}{ Alcohol use: AA score* } \\
\hline $\begin{array}{l}\text { One month prior } \\
\text { to conception }\end{array}$ & 0.96 & $(0.84)$ & 68 & 0.75 & $(0.73)$ & 68 \\
\hline During pregnancy & 0.14 & $(0.21)$ & 68 & 0.20 & $(0.33)$ & 68 \\
\hline $\begin{array}{l}\text { During lactation } \\
\text { month one }\end{array}$ & 0.41 & $(0.39)$ & 68 & 0.45 & $(0.54)$ & 68 \\
\hline $\begin{array}{l}\text { During lactation } \\
\text { month three }{ }^{\dagger}\end{array}$ & 0.57 & $(0.67)$ & 59 & 0.53 & $(0.47)$ & 64 \\
\hline \multicolumn{7}{|c|}{ Tobacco use: Average daily mg nicotine } \\
\hline During pregnancy & 3.6 & $(6.9)$ & 66 & 3.8 & $(6.8)$ & 65 \\
\hline $\begin{array}{l}\text { During lactation } \\
\text { month one }\end{array}$ & 4.7 & $(8.2)$ & 66 & 4.5 & (7.9) & 67 \\
\hline $\begin{array}{c}\text { During lactation } \\
\text { month three } \dagger\end{array}$ & 6.2 & $(9.2)$ & 57 & 5.3 & $(8.0)$ & 64 \\
\hline \multicolumn{7}{|l|}{ Cocaine use: Frequency } \\
\hline \multicolumn{7}{|l|}{ During pregnancy } \\
\hline never & & & 59 & & & 65 \\
\hline$<$ once a month & & & 8 & & & 3 \\
\hline 2-3 times a month & & & 1 & & & 0 \\
\hline \multicolumn{7}{|c|}{ During lactation month one } \\
\hline never & & & 65 & & & 68 \\
\hline <once a month & & & 2 & & & 0 \\
\hline once a month & & & 1 & & & 0 \\
\hline \multicolumn{7}{|c|}{ During lactation month three $f$} \\
\hline never & & & 60 & & & 62 \\
\hline once a month & & & 1 & & & 2 \\
\hline unknown & & & 7 & & & 4 \\
\hline
\end{tabular}

*The AA score reflects the absolute ounces of ethanol ingested daily.

†Eleven subjects selected too late for the third month interview.

juana during lactation. The Pearson correlation coefficients between these variables were all less than .08 . There was also no significant correlation between marijuana use during lactation and consumption of coffee.

For descriptive purposes, the mean MDI and PDI scores, stratified by infant marijuana exposure, are presented in Table 5. Higher exposure was defined as exposure to marijuana for more than half of the days of the period. Infants exposed to marijuana for more than half of the days during the first trimester or the first month of lactation had significantly lower mean PDI scores than infants with no marijuana exposure during these periods (one-way ANOVA, $p=0.02$, and 0.008 , respectively). Moderate marijuana exposure (exposure for no more than half of the days in a period) only appeared to affect infant PDI in the first trimester. Mean infant PDI scores decreased linearly with increasing marijuana exposure during this period (linear trend, $p=0.005$ ). Very little change was reflected in the mean mental score.

When the secondary independent variables listed above were examined to determine if they might be the cause of the difference in PDI seen in Table 5, only the measure of maternal marijuana use during pregnancy was a potential confounder. Maternal race (white versus nonwhite) demonstrated a near significant association with both lactation exposure and infant motor development and was retained for further study.

Variables initially regressed on infant motor development (PDI) were maternal race and the number of days that infants were exposed to marijuana during each trimester and the first and third months of lactation. Of these variables, infant exposure to marijuana via the mother's milk during the first month postpartum was the only variable identified by stepwise and backward selection that explained a significant proportion of the variance in infant motor development (Table 6). Five percent of the variance was explained by the infant's exposure to marijuana during this period. Infant exposure expressed as the number of joints smoked by the mother during lactation did not change the results.

The only variables regressed on infant mental development were the number of days that infants were exposed to marijuana during lactation months one and three because no secondary variables were identified as confounders. No significant associations were found.

Exposure to cocaine via breast milk and alcohol during gestation also had a significant adverse effect on infant PDI (Table 
TABLE 5

MEAN MOTOR AND MENTAL DEVELOPMENT SCORES* CORRESPONDING WITH MARIJUANA EXPOSURE DURING GESTATION AND LACTATION

\begin{tabular}{|c|c|c|c|c|c|c|c|}
\hline \multirow{2}{*}{$\begin{array}{l}\text { Days of Infant } \\
\text { Marijuana Exposure }\end{array}$} & & \multicolumn{3}{|c|}{$\begin{array}{c}\text { Motor Development } \\
\text { PDI }\end{array}$} & \multicolumn{3}{|c|}{$\begin{array}{l}\text { Mental Development } \\
\text { MDI }\end{array}$} \\
\hline & & Mean & (S.D.) & Range & Mean & (S.D.) & Range \\
\hline \multicolumn{8}{|l|}{ Trimester one $\uparrow$} \\
\hline 0 & $(n=84)$ & 105 & (17) & $70-150$ & 107 & (15) & $72-150$ \\
\hline 1 to 44 & $(n=36)$ & 99 & (17) & $66-147$ & 108 & (15) & $77-134$ \\
\hline 45 to 90 & $(n=16)$ & 93 & (16) & $75-136$ & 106 & (13) & $89-128$ \\
\hline \multicolumn{8}{|l|}{ Trimester two } \\
\hline 0 & $(\mathrm{n}=98)$ & 102 & (17) & $66-150$ & 106 & (15) & $72-150$ \\
\hline 1 to 44 & $(\mathrm{n}=25)$ & 104 & (19) & $66-147$ & 111 & (12) & $86-128$ \\
\hline 45 to 90 & $(n=13)$ & 94 & (16) & $76-136$ & 106 & (14) & $84-128$ \\
\hline \multicolumn{8}{|l|}{ Trimester three } \\
\hline 0 & $(\mathrm{n}=94)$ & 101 & (17) & $66-150$ & 107 & (15) & $72-150$ \\
\hline 1 to 44 & $(\mathrm{n}=28)$ & 107 & (17) & $86-147$ & 109 & (14) & $86-128$ \\
\hline 45 to 90 & $(n=14)$ & 94 & (16) & $76-136$ & 106 & (14) & $84-128$ \\
\hline \multicolumn{8}{|l|}{ Lactation month onef } \\
\hline 0 & $(\mathrm{n}=81)$ & 102 & (18) & $66-150$ & 109 & (15) & $77-150$ \\
\hline 1 to 14 & $(\mathrm{n}=38)$ & 106 & (16) & $82-145$ & 105 & (12) & $84-128$ \\
\hline 15 to 30 & $(n=17)$ & 90 & (14) & $66-117$ & 106 & (15) & $72-128$ \\
\hline \multicolumn{8}{|c|}{ Lactation month three } \\
\hline 0 & $(n=84)$ & 102 & (18) & $66-150$ & 107 & (15) & $77-150$ \\
\hline 1 to 14 & $(\mathrm{n}=28)$ & 103 & (16) & $71-134$ & 110 & (13) & 89-134 \\
\hline 15 to 30 & $(\mathrm{n}=13)$ & 97 & (16) & $76-136$ & 108 & (17) & $72-128$ \\
\hline
\end{tabular}

*Motor and mental developmental scores (PDI, MDI) were from the Bayley Scales of Infant Development.

†PDI decreased with increasing marijuana exposure, test for linear trend, $p=0.005$.

$¥$ Mean PDI for the higher exposure group was lower than the PDI for the no or low exposure groups, one-way ANOVA $p=0.008$.

$\S$ Eleven subjects selected too late for third month interview.

7). Inclusion of cocaine and alcohol exposure variables in the above model explained an additional nine percent of the variance in infant PDI scores. Alcohol and cocaine exposure did not confound or interact with the effect of marijuana exposure during lactation on infant PDI, nor did the removal of the five subjects with reported cocaine use during lactation.

Thirty-eight of the 136 women reported use of supplemental formula (less than 16 ounces per day) during the first and/or the third month of lactation. Twenty-two of these women were in the marijuana-exposed group. In this study, women who used less than 16 ounces of supplemental formula during lactation were classified with the women who reported no use of supplemental formula. This classification scheme could result in a slight overestimate of infant marijuana exposure via breast milk, and thus underestimate the strength of the relationship between marijuana exposure and infant development. Restricting the analysis to those women who reported no use of supplemental formula at any time $(n=98)$ did, in fact, strengthen the association between marijuana exposure during the first month of lactation and infant motor development. Eight percent of the variance in infant motor development was explained by the infant's exposure to marijuana during this period, $\mathrm{F}(2,87)=7.3, p=0.001$. Exposure to cocaine throughout lactation explained an additional six percent of the variance. Alcohol exposure during gestation no longer explained a significant amount of the variance in infant motor development in this subset of infants.

\section{DISCUSSION}

In this study sample, daily infant exposure to marijuana via the mother's milk during postpartum month one was associated with a $14 \pm 5$ point decrease in the Bayley index of infant motor development. This adverse effect on infant PDI was noted in spite of the low-risk status of the study population. The finding persists after controlling for maternal smoking, drinking and cocaine use during pregnancy and lactation.

Marijuana exposure during the first trimester, however, confounded the association between marijuana exposure during the first month of lactation and infant PDI. Stepwise and backwards variable selection procedures identified marijuana exposure during the first month of lactation as the stronger predictor of infant PDI, but the strong correlation between marijuana exposure during the first trimester of pregnancy and the first month of lactation makes it difficult to reliably determine which period of exposure had a stronger influence on infant motor development.

One way to assess the relative importance of independent variables is to consider the increase in $r^{2}$ when a variable is entered into an equation that already contains the other independent 
TABLE 6

MATERNAL RACE AND INFANT MARIUUANA EXPOSURE DURING GESTATION AND LACTATION REGRESSED ON INFANT PDI

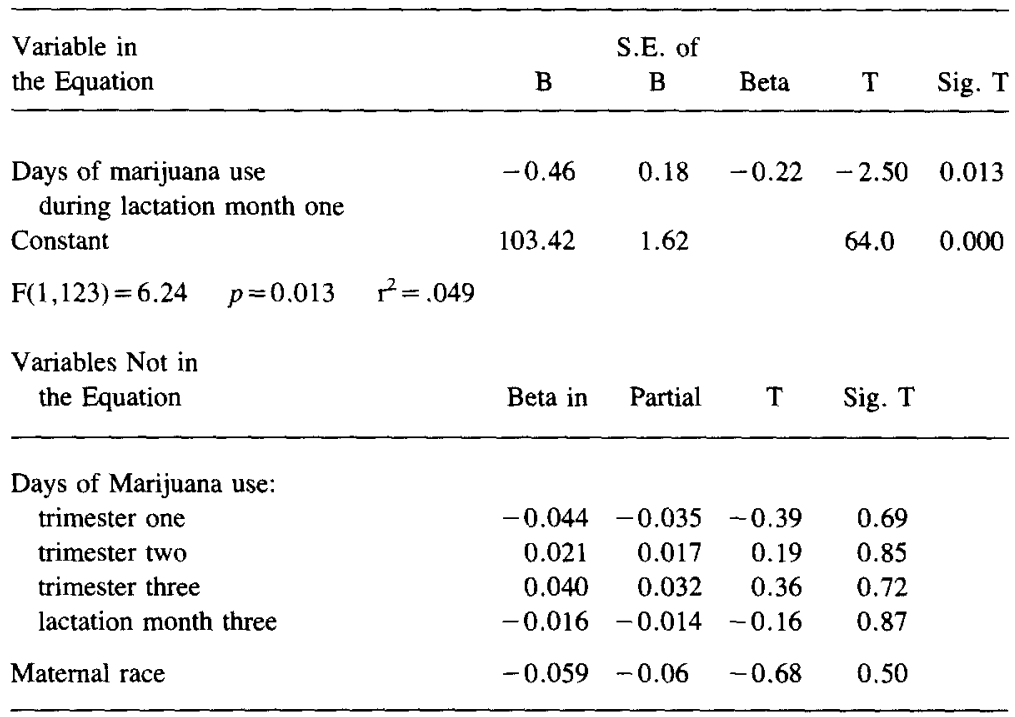

Dependent variable: PDI (infant Psychomotor Developmental Index from the Bayley Scales of Motor Development).

variables (16). A large change in $r^{2}$ indicates that a variable provides unique information about the dependent variable that is not available from the other independent variables in the equation. The addition of first trimester marijuana exposure to a model containing marijuana exposure during the first month of lactation resulted in a change in $\mathrm{r}^{2}$ of only .001 (Table 8). On the other hand, the addition of the first month lactation exposure to a model containing first trimester marijuana exposure resulted in a change in $r^{2}$ of .023 suggesting that marijuana exposure during the first month of lactation contributes unique information about the variance in infant PDI, above and beyond the information provided by first trimester exposure. Further evidence suggesting a weak or perhaps nonexistent association between first trimester exposure and infant PDI can be seen in the low F value when first trimester exposure is regressed separately on infant PDI.

TABLE 7

VARIABLES IDENTIFIED BY STEPWISE MULTIPLE REGRESSION, THAT EXPLAINED A SIGNIFICANT PROPORTION OF THE VARIANCE IN INFANT PDI

\begin{tabular}{lccccc}
\hline Independent & & S.E. of & & Sig. \\
Variables & B & B & T & T & $r^{2}$ \\
\hline
\end{tabular}

$\begin{array}{llllll}\begin{array}{l}\text { Days of marijuana use } \\ \text { during lactation month one }\end{array} & -0.46 & 0.18 & -2.58 & 0.011 & .05 \\ \begin{array}{l}\text { Pregnancy AA score* } \\ \begin{array}{l}\text { Days of cocaine use } \\ \text { throughout lactation }\end{array}\end{array} & -13.85 & 5.21 & -2.66 & 0.009 & .05 \\ \begin{array}{l}\text { Constant } \\ \mathrm{F}(3,121)=6.54 \quad p=0.0004\end{array} & 106.23 & 1.81 & 58.4 & 0.000 & \\ \end{array}$

*The AA score reflects the absolute ounces of ethanol ingested daily. Dependent variable: PDI (infant Psychomotor Developmental Index from the Bayley Scales of Motor Development).
A linear model provided the best fit of the data, despite the threshold appearance of the relationship between marijuana exposure during the first month of lactation and infant motor development (Table 5). A linear fit is certainly not inconsistent with the results presented in Table 5 . When continuous data is presented in a categorized format, an apparent threshold or linear effect can be created simply by virtue of where you decide to divide the categories. Further study, preferably with larger samples will be

TABLE 8

MARIJUANA EXPOSURE DURING THE FIRST TRIMESTER OF PREGNANCY AND THE FIRST MONTH OF LACTATION REGRESSED ON INFANT PDI*

Days of first trimester marijuana exposure regressed on infant PDI

$\mathrm{PDI}=102.9-0.12(\mathrm{mj}-1 \mathrm{st}$ trimester $)$

$$
\begin{array}{rr}
\text { S.E. }=0.07 & \mathrm{~F}(1,134)=3.67 \\
p=0.07 & p=0.07 \\
\mathrm{r}^{2}=.026
\end{array}
$$

Days of marijuana exposure during lactation month one regressed on infant PDI

$\mathrm{PDI}=103.4-0.46($ mj-lactation $)$

$$
\begin{array}{rl}
\text { S.E. }=0.18 & \mathrm{~F}(1,134)=6.80 \\
p=0.01 & p=0.01 \\
\mathrm{r}^{2}=.049
\end{array}
$$

Days of marijuana exposure during trimester one and lactation month one regressed simultaneously on infant PDI

$\mathrm{PDI}=103.5-0.03(\mathrm{mj}-1$ st trimester $)-0.41$ (mj-lactation)

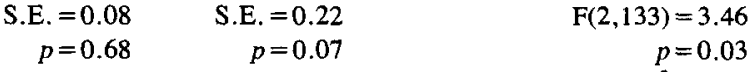

$$
\begin{aligned}
& \mathrm{r}^{2}=.050
\end{aligned}
$$

*PDI: Psychomotor Development Index from the Bayley Scales. 
necessary to determine the true nature of the association between PDI and marijuana exposure via breast milk.

To date, only one published report has assessed the relationship between infant exposure to marijuana via breast milk and infant development at one year of age (18). In this study, Tennes and her colleagues compared a subset of 27 infants exposed to marijuana via breast milk to 35 breast-fed infants who were not exposed to marijuana. Of the women that reported marijuana use during lactation, twelve used it once a month or less, nine reported weekly use and six used it daily. Prenatal marijuana exposure was not reported for this group. At one year of age the infants were assessed for motor and mental skills using the Bayley Scales of Infant Development. Unlike the present study, no apparent effects of postnatal marijuana exposure were found. The investigators did note, however, that the statistical analyses were limited due to the small sample size and lack of comparability among cases for duration of exposure and dose.

In a study of prenatal effects of marijuana exposure on infant development (2), Fried reported that babies born to women who smoked more than five joints per week during pregnancy demonstrated marked tremors and startles and altered visual responsiveness at two to four days of age. These symptoms attenuated within 30 days. A follow-up study found no association between prenatal marijuana exposure and infant motor development (PDI) at one and two years of age (5). In the present study, prenatal marijuana exposure also failed to be associated with infant motor development when measured at one year of age. Postnatal marijuana exposure, however, did appear to be significantly associated with one-year motor development scores in the present study. Measures of postnatal marijuana exposure were not available in the two studies reported by Fried.

Despite the slight increase in maternal use of marijuana during the third month of lactation in the present study, there was no significant effect on infant PDI associated with marijuana use at that time. It is unlikely that this is due to the decrease in the sample size by eleven subjects in the third month postpartum. The study had the power to detect a difference of eight points in the motor development index with ninety percent certainty in the third month. An increase in the use of supplemental formula also failed to explain the lack of association between infant motor development and marijuana exposure during the third month of lactation. Use of supplemental formula would reduce infant marijuana exposure via breast milk, but exclusion of women who used supplemental formula failed to strengthen the association. This lack of effect on infant PDI may reflect a decrease in developmental vulnerability in postpartum month three.

Maternal use of marijuana during pregnancy and lactation had no detectable effect on infant mental development at one year of age in this study. A lack of association between prenatal exposure and mental development at one and two years of age has also been reported by Fried $(2,5)$. The lack of association seen in all three studies suggests that the neurological areas associated with cognitive function may be less vulnerable to marijuana exposure. Further studies using larger sample sizes, higher exposure and more sensitive diagnostic tools are needed to support this finding.

Daily exposure to marijuana during the first month of lactation was associated with a decrease in PDI score of 14 points, which represents three quarters of a standard deviation in the infants of this sample. It is a difference large enough to be detected by an astute clinician. The long-term implications for child development, however, are unknown. Evaluation of infant mental and motor development is not straightforward, and interpretation of the findings is not always easy.

In summary, although marijuana exposure during lactation was associated with decreased infant motor development, this result should be interpreted cautiously due to the preliminary nature of this study. One cannot infer from the results presented here that marijuana exposure during lactation impairs infant motor development at one year of age, or that prenatal marijuana exposure does not impair motor development. Marijuana exposure during lactation appeared to be a better predictor of infant motor development, but it does not necessarily mean that the relationship is one of cause and effect. Prenatal marijuana exposure, passive exposure to marijuana smoke in the air and the quality of maternal/infant interactions are three factors that could potentially confound the observed association in this study. The difficulty of evaluating infant development and the predictive value of the findings should also be considered. Nevertheless, the deleterious effects of maternal drug use on infant development may not be limited to prenatal exposure; postnatal exposure may be playing a critical role and warrants consideration in future investigations.

\section{ACKNOWLEDGEMENTS}

This research was funded by the Alcoholism and Drug Abuse Institute, with partial support from NIH Grant No. HD14689. We are grateful to Group Health Cooperative of Puget Sound for their assistance with this project.

\section{REFERENCES}

1. Bayley, N. Bayley scales of infant development. New York: The Psychological Corporation; 1969.

2. Fried, P. A. Marihuana use by pregnant women and effects on offspring: An update. Neurobehav. Toxicol. Teratol. 4:451-454; 1982.

3. Fried, P. A. Marihuana use by pregnant women: neurobehavioral effects in neonates. Drug Alcohol Depend. 6(6):415-424; 1980.

4. Fried, P. A.; Barnes, M. V.; Drake, E. R. Soft drug use after pregnancy compared to use before and during pregnancy. Am. J. Obstet. Gynecol. 151(6):787-792; 1985

5. Fried, P. A.; Watkinson, B. 12- and 24-month neurobehavioural follow-up of children prenatally exposed to marihuana, cigarettes and alcohol. Neurotoxicol. Teratol. 10:305-313; 1988.

6. Fried, P. A.; Watkinson, B.; Grant, A.; Knights, R. M. Changing patterns of soft drug use prior to and during pregnancy: A prospective study. Drug Alcohol Depend. 6:323-343; 1980.

7. Gibson, G. T.; Baghurst, P. A.; Colley, D. P. Maternal alcohol, tobacco and cannabis consumption and the outcome of pregnancy. Aust. N. Z. J. Obstet. Gynecol. 23:15-19; 1983.

8. Greenland, S.; Richwald, G. A.: Honda, G. D. The effects of marijuana use during pregnancy. II. A study in a low-risk home- delivery population. Drug Alcohol Depend. 11:359-366; 1983.

9. Greenland, S.; Staisch, K. J.; Brown, N.; Gross, S. J. Effects of marijuana on human pregnancy, labor, and delivery. Neurobehav. Toxicol. Teratol. 4:447-450; 1982 .

10. Hingson, R.; Alpert, J. J.; Day, N.; Dooling, E.; Kayne, H.; Morelock, S.; Oppenheimer, E.; Zuckerman, B. Effects of maternal drinking and marijuana use on fetal growth and development. Pediatrics 70(4):539-546; 1982.

11. Jessor, R.; Graves, T. D.; Hanson, R. C.; Jessor, S. L. Society, personality and deviant behavior: a study of a tri-ethnic community. New York: Holt, Rinehart and Winston; 1968.

12. Little, R. E.; Anderson, K. W.; Ervin, C. H.; Worthington-Roberts, B.; Clarren, S. K. Maternal alcohol use during breast-feeding and infant mental and motor development at one year. N. Engl. J. Med. 321(7):425-430; 1989.

13. Little, R. E.; Uhl, C. N.; Labbe, R. S.; Abkowitz, J. L.; Phillips, E. L. R. Agreement between laboratory tests and self reports of alcohol, tobacco, caffeine, marijuana and other drug use in post-partum women. Soc. Sci. Med. 22:91-98; 1986.

14. Little, R. E.; Lambert, M. D.; Worthington-Roberts, B. Postpartum drinking and smoking: Differences by lactation history. Paed. Perinat. 
Epidemiol.; in press.

15. Little, R. E.; Worthington-Roberts, B.; Mann, S. L.; Uhl, C. N. Test-retest reliability of diet and drinking estimates for pregnancy and post partum. Am. J. Epidemiol. 120:794-797; 1984

16. Norusis, M. J. SPSS PCC + for the IBM PCXTAT. SPSS Inc., Chicago; 1986.

17. Perez-Reyes, M.; Wall, M. E. Presence of delta-9-tetrahydrocannabinol in human milk. N. Engl. J. Med. 307:819-820; 1982.

18. Tennes, K.; Avitable, N.; Blackard, C.; Boyles, C.; Hassoun, B. Holmes, L.; Kreye, M. Marijuana: Prenatal and postnatal exposure in the human. Natl. Inst. Drug Abuse Res. Monogr. 59:48-60; 1985.
19. Worthington-Roberts, B.; Little, R. E.; Lambert, M. D. Factors predicting dietary quality of postpartum women. Nutr. Rep. Int. 39(4):673-685; 1989.

20. Worthington-Roberts, B.; Little, R. E.; Lambert, M. D.; Wu, R. Dietary cravings and aversions in the postpartum period. J. Am. Diet. Assoc. 89(5):647-651; 1989.

21. Zuckerman, B.; Frank, D. A.; Hingson, R.; Amaro, H.; Levenson, S M.; Kayne, H.; Parker, S.; Vinci, R.; Aboagye, K.; Fried, L. E.; Cabral, H.; Timperi, R.; Bauchner, H. Effects of maternal marijuana and cocaine use on fetal growth. N. Engl. J. Med. 320(12):762-768; 1989. 